\title{
Interventional study to improve adherence to phosphate binder treatment in dialysis patients
}

Bodil Jahren Hjemås ${ }^{1 *}$ (D), Katrine Bøvre ${ }^{1}$, Liv Mathiesen², Jonas Christoffer Lindstrøm ${ }^{3}$ and Kathrin Bjerknes ${ }^{1}$

\begin{abstract}
Background: Adherence to phosphate binder treatment is important to prevent high serum phosphate level in chronic dialysis patients. We therefore wanted to investigate patient knowledge, beliefs about and adherence to phosphate binders among these patients and assess whether one-to-one pharmacist-led education and counselling enhance adherence and lead to changes in serum phosphate levels.
\end{abstract}

Methods: A descriptive, interventional, single arm, pre-post study was performed at a hospital in Norway, including chronic dialysis patients aged 18 years or more using phosphate binders. The primary end-point was change in the proportion of patients with serum phosphate below $1.80 \mathrm{mmol} / \mathrm{L}$ and the secondary end-points included change in the patient's knowledge, beliefs and adherence after the intervention measured by completion of questionnaires 'Patient Knowledge', Medication Adherence Report Scale (MARS-5) and Beliefs about Medicines Questionnaire (BMQ). Data was collected both prior to and after one-to-one pharmacist-led education and counselling about their phosphate binders. Other medicines used by the patient was also registered.

Results: A total of 69 patients were enrolled in the study. After intervention, the probability of serum phosphate being below the target threshold $1.80 \mathrm{mmol} / \mathrm{L}(5.58 \mathrm{mg} / \mathrm{dL})$ increased, although no significant change in mean serum phosphate levels was seen. On the other hand, the knowledge regarding phosphate binder treatment and the patients' beliefs about the necessity of the treatment increased, while the concerns decreased (BMQ). This effect did not lead to increase in self-reported adherence measured by MARS-5. However the scores were high before the intervention.

Conclusions: Short term one-to-one individualized pharmacist-led education and counselling about phosphate binders increased the probability of serum phosphate concentrations being below the target threshold level 1.80 $\mathrm{mmol} / \mathrm{L}(5.58 \mathrm{mg} / \mathrm{dL})$, although not statistically significant. However, it did not decrease the mean serum phosphate level or increase the patients' self-reported adherence. The patients increased their knowledge about the phosphate binder and their understanding of adherence, and were less concerned about the side effects of the medication.

Trial registration: ISRCTN52852596, registered 11 April 2019. The trial was registered retrospectively.

Keywords: Adherence, Beliefs about medicines, Hemodialysis, Hyperphosphatemia, Phosphate binder, Pharmacist led education

\footnotetext{
*Correspondence: bodil.jahren.hjemas@sykehusapotekene.no

${ }^{1}$ Hospital Pharmacies Enterprise, South Eastern Norway, Stenersgate 1, PB. 79,

0050 Oslo, Norway

Full list of author information is available at the end of the article
}

(c) The Author(s). 2019 Open Access This article is distributed under the terms of the Creative Commons Attribution 4.0 International License (http://creativecommons.org/licenses/by/4.0/), which permits unrestricted use, distribution, and reproduction in any medium, provided you give appropriate credit to the original author(s) and the source, provide a link to the Creative Commons license, and indicate if changes were made. The Creative Commons Public Domain Dedication waiver (http://creativecommons.org/publicdomain/zero/1.0/) applies to the data made available in this article, unless otherwise stated. 


\section{Background}

Hyperphosphatemia is present in the majority of dialysis patients and is associated with increased risk of cardiovascular mortality [1-3]. Drug treatment with phosphate binders is therefore indicated in most chronic dialysis patients, but adherence is often poor $[4,5]$.

In a systematic review including 44 publications, the prevalence of medication non-adherence varied from 12.5-98.6\% [6]. Different definitions and methods as well as many factors influencing adherence made the picture complex. Factors associated with non-adherence were both patient related, medication related and disease related, including illness interfering family life, longevity of hemodialysis, depressive symptoms and complexity of medication regimen.

Adherence to medication regimes in patients with chronic kidney disease (CKD) has been found to correlate with beliefs about medicines in a study using the validated tool Beliefs about Medicines Questionnaire (BMQ) [7]. The Medication Adherence Report Scale (MARS) has been developed to explore self-reported adherence [8]. These tools were applied in a previous study including 160 patients with CKD. Adherence was associated positively with family and work status as well as patient's concerns about medicine measured by BMQ [9].

The correlation between medication beliefs measured by BMQ, self reported adherence measured by MARS and serum phosphate in hyperphosphatemic haemodialysis patients was studied in a randomized controlled trial [10]. They found that medication necessity beliefs explained the variance of serum phosphate and self-reported adherence. The authors pointed out that "Dialysis patient's medication beliefs are potentially modifiable targets for future interventions".

Studies including different interventions like one-to one educational sessions, telephone-calls, demonstration and leaflets has to variable degrees been successful in improving adherence to phosphate binders and lowering of serum phosphate levels [4, 11-14]. The lack of consistence in results between the studies as well as the overall complex picture of numerous factors influencing adherence, underlines the need of further research to increase the evidence for practice in this area. Pharmacist-led education and counselling can be one strategy to modify beliefs about medications and hence increase adherence to phosphate binder treatment in dialysis patients.

The aim of this study was to investigate knowledge, beliefs about and adherence to phosphate binders among chronic dialysis patients and to assess whether one-to-one pharmacist-led education and counselling could improve phosphate binder adherence and lead to changes in serum phosphate levels.

\section{Methods}

A descriptive, interventional, single arm, pre-post study was performed at Akershus University Hospital in Norway, recruiting patients at the dialysis centre during May and June 2017. Chronic dialysis patients using phosphate binders received written and oral information about the study. Eligibility criteria were: 1) age $>18$ years, 2) receiving chronic dialysis two to four times a week for at least 5 months, 3) life expectancy $>5$ months, 4) using at least one self-administered phosphate binder, 5) able to speak, read and write Norwegian, and 6) able to give informed consent. Demographic characteristics, medical and pharmacological data were collected from the medical record and by face-to-face interview.

The collection of data was done twice; before and after the intervention. The primary end-point was change in the proportion of patients with serum phosphate below $1.80 \mathrm{mmol} / \mathrm{L}(5.58 \mathrm{mg} / \mathrm{dL})$. The secondary end-points were to assess whether the patients' knowledge, beliefs and adherence changed. In addition, other medicines used by the patient were registered to see whether the use of psycholeptic and/or psychoanaleptic medicine correlated with serum phosphate levels, adherence and beliefs.

Pre-dialytic (not fasting) values of serum phosphate is monthly monitored at the hospital and registered in the medical record. In the study, data on serum phosphate levels for 5 months prior to the intervention, and 5 months after were drawn from the medical records for included patients.

A serum phosphate target threshold $<1.80 \mathrm{mmol} / \mathrm{L}$ $(5.58 \mathrm{mg} / \mathrm{dL})$ was set in consistence with the hospital guidelines referring to UpToDate and the Kidney Disease Outcomes Quality Initiative guidelines (KDOQI) $[15,16]$.

One study pharmacist executed a half-hour one-to-one intervention, comprising a single session education and personalized counselling about the use of phosphate binders, as outlined in Table 1 . The intervention was performed at the hospital dialysis centre during dialysis treatment, 2-3 weeks after inclusion of each patient. A semi-structured counselling guide, partly based on the script used in the study by Van Camp et al [11], was used in the education and counselling. In addition, an educational leaflet based on this guide was offered to the patients. This included information about phosphate and functions in the body, foods containing phosphate, how we can get too much phosphate and what consequences this might have. It also contained information about the phosphate binder: effect, importance, practical information regarding intake, possible side effects and interactions with other medicines.

During the study period, the usual care regarding education and counselling specific to phosphate and phosphate binder treatment was continued in the dialysis unit. This included physician counselling and 
Table 1 Key elements of the pharmacist-led education and counselling. 'Educational leaflet partially based on the phosphate binders pamphlet used by van Camp et al. [11]

\begin{tabular}{|c|c|c|c|}
\hline Format of & Single one to $o$ & session & \\
\hline Timing & $\begin{array}{l}\text { Week } 2 \text { or } 3 \\
\text { after inclusion }\end{array}$ & $15-20$ minutes & $10-15$ minutes \\
\hline \multirow[t]{11}{*}{$\begin{array}{l}\text { Content of } \\
\text { session }\end{array}$} & & $\begin{array}{l}\text { In-person education: } \\
\text { Semi-structured education based on phosphate } \\
\text { binders information leaflet }{ }^{1} \text {, regarding each of the } \\
\text { following questions: }\end{array}$ & $\begin{array}{l}\text { Personalized counselling: } \\
\text { Individual counselling with open questions to gain } \\
\text { understanding of medication taking behavior, by } \\
\text { questions like "How was your phosphate binder } \\
\text { intake lately?" }\end{array}$ \\
\hline & & What is phosphate? & \\
\hline & & $\begin{array}{l}\text { What foods are rich in phosphate? } \\
\text { What effects does phosphate have in the body? } \\
\text { How can we get too much phosphate? }\end{array}$ & $\begin{array}{l}\text { Finding actions necessary to increase adherence, by } \\
\text { questions like "What caused you to miss these } \\
\text { doses?" }\end{array}$ \\
\hline & & What happens if we get to much phosphate? & -An example of such an action was providing a \\
\hline & & How do phosphate binders work? & proper container to bring tablets when eating at \\
\hline & & Why are phosphate binders important? & restaurants. \\
\hline & & How should we take the phosphate binder? & \\
\hline & & What side effects may phosphate binders cause? & \\
\hline & & $\begin{array}{l}\text { Can we take phosphate binders together with other } \\
\text { medicines? }\end{array}$ & \\
\hline & & $\begin{array}{l}\text { The information leaflet }{ }^{1} \text { was offered to the patient to } \\
\text { bring home. }\end{array}$ & \\
\hline & & $\begin{array}{l}\text { Additional patient tailored information on phosphate } \\
\text { binders }\end{array}$ & \\
\hline
\end{tabular}

information (oral and written) related to serum phosphate monitoring and when starting or changing phosphate binder treatment.

The participants were asked to answer the three questionnaires ('Patient Knowledge', MARS-5 and BMQ) twice; at the time of inclusion and 3-4 weeks after the intervention. The patients answered the questionnaires during dialysis treatment.

The competence in the study group regarding phosphate binder ('Patient Knowledge') was assessed by an eight-item multiple-choice questionnaire based on the questionnaire developed by Eide et al [17], as outlined in (Fig. 1). The questionnaire was evaluated by the hospital user representative and one dialysis patient. The usability was assessed by letting two other dialysis patients fill out the questionnaire and state if they understood the questions or not. Some minor changes in format was included before start of the main study.

Adherence was measured with the MARS-5 [18] and permission to use the scale was provided by Professor Robert Horne. The original scale consists of general statements about medicines, and in this study the statements were specified with the term phosphate binder. The MARS-5 is a 5-item self-report scale and the responses are scored on a 5 -point Likert- scale where $1=$ always, $2=$ often, $3=$ sometimes, $4=$ rarely, and $5=$ never. Total scores for the whole questionnaire range from 5 to 25, with higher scores indicating higher self-reported adherence.

The patients' perception of medication was measured by BMQ, consisting of two sections, BMQ-Specific, which assesses beliefs about the necessity and concerns for personal medicines, and BMQ-General, which assesses general beliefs about overuse and harm of medicines. Responses are scored on a 5-point Likert-scale. Scores for the individual items within each scale were summed to give a total score, ranging from 6 to 30 for the 'Necessity scale', 5 to 25 for the 'Concerns scale' and 4 to 20 for the 'Overuse and Harm scales'. Higher scores indicate stronger beliefs in the concepts represented by the scale. The validated Norwegian translations of the MARS-5 and the BMQ were used in this study $[19,20]$.

Change in serum phosphate concentrations after the intervention was analysed with a linear mixed model, with a per patient random intercept to account for the repeated measurements before and after the intervention. A logistic mixed model was used to analyse the change in probability of serum phosphate concentrations being below $1.80 \mathrm{mmol} / \mathrm{L}$. Linear mixed effects models were also used to analyse the effect of the intervention on the secondary outcomes. Correlations were also estimated with mixed effect models, where the serum 


\section{Questionnaire «Knowledge regarding phosphate binders» Mark the answers you find to be correct. There may be several answers to one question. The questionnaire has two pages with a total of eight questions. \\ 1. For what condition do you receive phosphate binder? \\ a. High blood pressure \\ b. Diabetes \\ c. High serum phosphate \\ d. Low serum phosphate \\ e. I do not know \\ 2. How does the phosphate binder work?

$$
\begin{aligned}
& \text { a. Lower the blood pressure } \\
& \text { b. Lower the blood sugar level } \\
& \text { c. Lower the serum phosphate level } \\
& \text { d. Increase the serum phosphate level }
\end{aligned}
$$$$
\text { e. I do not know }
$$ \\ 3. What would you want to prevent by using phosphate binders? \\ a. Itches of the skin \\ b. Red eyes \\ c. Development of diabetes \\ d. Heart attack \\ e. I do not know \\ 4. When should you take your phosphate binder?

$\begin{array}{ll}\text { a. } & \text { In the evening } \\ \text { b. In the morning } \\ \text { c. } & \text { For each meal } \\ \text { d. It dose not matter } \\ \text { e. I do not know }\end{array}$

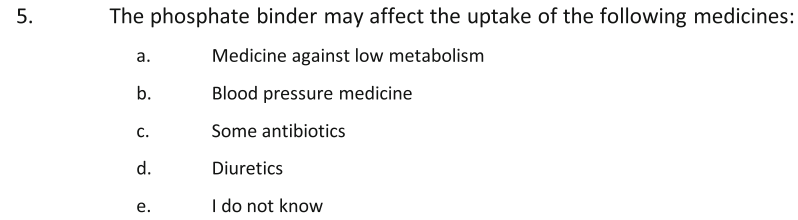

5. The phosphate binder may affect the uptake of the following medicines:

a. Medicine against low metabolism

b. Blood pressure medicine

c. Some antibiotics

d. Diuretics

e. I do not know \\ 6. What might be symptoms of side effects of the phosphate binders?

$$
\begin{array}{ll}
\text { a. } & \text { Nausea } \\
\text { b. } & \text { Vomiting } \\
\text { c. } & \text { Constipation } \\
\text { d. } & \text { Head ache } \\
\text { e. } & \text { I do not know }
\end{array}
$$ \\ 7. What should you do if you have forgotten to take your phosphate binder?

$$
\begin{aligned}
& \text { a. Take double dose with the next meal } \\
& \text { b. Take the next dose as normal with a meal } \\
& \text { c. It dose not matter if you forget a dose } \\
& \text { d. I do not know } \\
& \text { e. Take half dose at with the next meal }
\end{aligned}
$$ \\ 8.}

Fig. 1 The multiple choice 'Patient Knowledge' questionnaire. One point was given for each correct answer giving a potential total score of 16.0

phosphate concentrations were used as response and the secondary outcomes used as predictor variables. For these analyses the variables were standardized so that the coefficients could be interpreted as correlations. Associations between type of phosphate binder and patient knowledge and concerns before and after the intervention were tested using t-tests. Newcombs test of difference in proportions was used to test the associations between being on target (average across the five phosphate measurements being less than 1.8) and type of phosphate binder and type of dialysis. All analyses were done in $\mathrm{R}$, using the lme4 package for the mixed effect models.

\section{Results}

At study start, 122 chronic patients attended the hospital dialysis centre. Of these, 74 met the eligibility criteria of which five patients refused to participate (Fig. 2). The main reason for not including patients was language difficulties, while kidney transplantation was the main reason for exclusion after enrolment. Demographic data for the 53 patients who completed the study are outlined in Table 2.

Sevelamer carbonate was the most commonly prescribed phosphate binder in the study group: as the only phosphate binder in $43 \%(n=23)$ of the patients, and in combination with another phosphate binder in $30 \%$ ( $n=$ 16) of the patients. Lanthanum carbonate or calcium carbonate was prescribed as the only phosphate binder in $21 \%(n=11)$ and $6 \%(n=3)$ of the patients, respectively. No associations were found neither before nor after intervention between the type of phosphate binder in use and the mean number of correct answers for 'Patient Knowledge', or the mean scores for 'Specific-Concerns'. Furthermore, the type of phosphate binder in use was not associated with having mean serum phosphate at target level. 


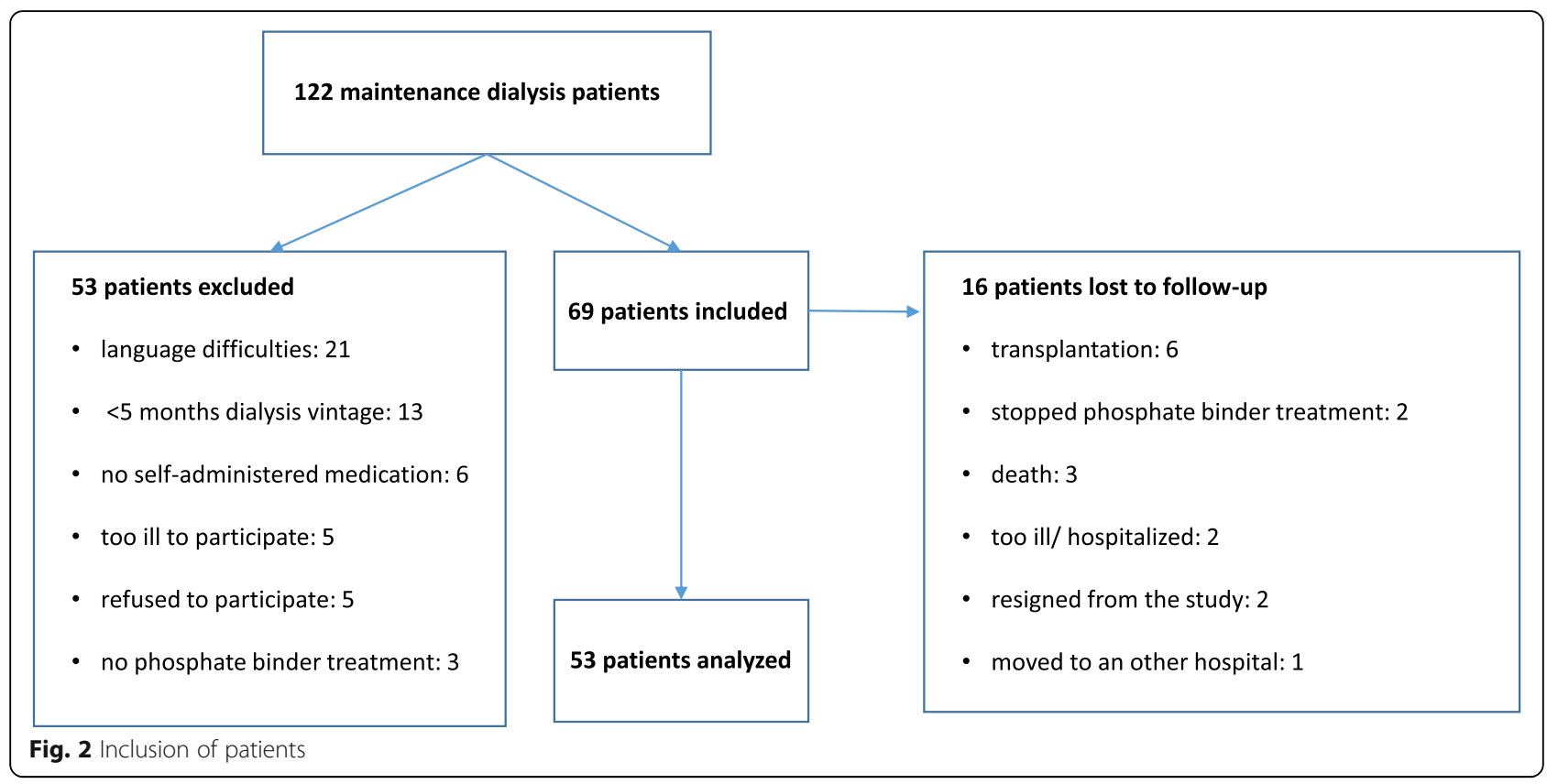

The serum phosphate values in the study group are outlined in Table 3. Based on the mean values for each patient before and after the intervention, it was estimated that the proportion of patients with serum phosphate concentration below the target threshold value $1.80 \mathrm{mmol} / \mathrm{L}(5.58 \mathrm{mg} / \mathrm{dL})$ increased from 45 to $49 \%$ in the total study group (odds ratio 1.27, 95\% CI: 0.81, 1.98; $p=0.294$, analysed by logistic mixed model). The mean levels were close to the target threshold $1.80 \mathrm{mmol} / \mathrm{L}$ $(5.58 \mathrm{mg} / \mathrm{dL})$ both prior to and after the intervention. No statistical change in serum phosphate was seen in the group after the intervention (mean change: 0.01

Table 2 Demographics of the study population $(n=53)$

\begin{tabular}{ll}
\hline Characteristics & \\
\hline Age in years, median, mean (range) & $72,68(21-93)$ \\
Female, n (\%) & $16(30)$ \\
Hemodialysis (HD), n (\%) & $37(70)$ \\
Hemodiafiltration (HDF), n (\%) & $16(30)$ \\
Dialysis months, median, mean (range) & $28,34(4-140)$ \\
Number of medicines, median, & $13,13(7-20)$ \\
mean (range) & \\
Patients using multidose drug dispensing & 11 \\
aid ${ }^{a}, \mathrm{n}$ & \\
Patients using N05 ${ }^{\mathrm{b}}=$ psycholeptics \\
and/or N06 ${ }^{\mathrm{b}}=$ psychoanaleptics, $\mathrm{n}$
\end{tabular}

${ }^{a}$ Multidose drug dispensing aid: meaning a sachet system where tablets and capsules for a particular date and dose time are packed in an individual sachet, labelled with date and time, the medicine details and the patient's name. Sachets are prepared using automated packing technology [38] ${ }^{b}$ WHO Anatomical Therapeutic Chemical (ATC) classification. Psycholeptics = antipsychotics, anxiolytics, hypnotics and sedatives. Psychoanaleptics $=$ antidepressants, psychostimulants and anti-dementia drugs $\mathrm{mmol} / \mathrm{L}(0.031 \mathrm{mg} / \mathrm{dL}), 95 \% \mathrm{CI}:-0.04,0.06 ; p=0.593) . \mathrm{A}$ subgroup analysis of the patients $(N=29)$ with mean serum phosphate level $>1.8 \mathrm{mmol} / \mathrm{L} \quad(5.58 \mathrm{mg} / \mathrm{dL})$ at baseline showed an increase in the proportion of patients with serum phosphate $<1.80 \mathrm{mmol} / \mathrm{L}(5.58 \mathrm{mg} /$ $\mathrm{dL}$ ) after intervention (proportion increased from 0 to $22 \%, N=6)$. However, no significant change was seen in mean serum phosphate after intervention (mean change: $0.05 \mathrm{mmol} / \mathrm{L}, 95 \%$ CI:-0.13, 0.03; $p=0.218$ ).

No associations were found neither before nor after intervention between the type of dialysis in use, hemodialysis (HD) versus hemodiafiltration (HDF), and the proportion of patients with mean serumphosphate at target level. The proportion of patients with mean serum phosphate at target level before intervention was $46 \%$ for those receiving $\mathrm{HD}(N=37)$ and $44 \%$ for those receiving HDF $(N=16)$. After intervention, the proportion was $49 \%$ and $50 \%$ respectively.

The mean total scores for MARS-5 in the study group was high both before (22.1) and after (22.5) the intervention. No statistical change was seen in self-reported adherence after intervention measured by MARS- 5 (mean change in total score: 0.415 , CI: $-0.304,1.134 ; p=0.258$ ). Some improvement in self-reported adherence was seen after intervention measured by decrease in the proportion of patients who reported non-adherent behaviour for the statement "I take less than instructed": $21 \%$ prior to and $11 \%$ after intervention. A patient was registered as non-adherent when "sometimes", "often" or "always" was answered to the statement.

The total score for each BMQ subscale before and after intervention are outlined in Table 4. On average, 
Table 3 Serum phosphate values before and after intervention

\begin{tabular}{lllll}
\hline $\begin{array}{l}\text { Time } e^{a} \text { relative to } \\
\text { intervention (month) }\end{array}$ & $\begin{array}{l}\text { Mean serum phosphate } \\
\mathrm{mmol} / \mathrm{L}(\mathrm{mg} / \mathrm{dL})(\mathrm{mean})\end{array}$ & $\begin{array}{l}\text { Serum phosphate } \\
\mathrm{mmol} / \mathrm{L}(\mathrm{mg} / \mathrm{dL})(\mathrm{range})\end{array}$ & $\begin{array}{l}\text { Serum phosphate } \mathrm{mmol} / \\
\mathrm{L}(\mathrm{mg} / \mathrm{dL})(\mathrm{median})\end{array}$ & $\begin{array}{l}\text { Serum phosphate below 1.80 mmol/L } \\
(5.58 \mathrm{mg} / \mathrm{dL})(\mathrm{proportion} \text { of patients) }\end{array}$ \\
\hline-5 & $1.80(5.58)$ & $0.90-3.01(2.79-9.33)$ & $1.75(5.43)$ & 0.54 \\
-4 & $1.85(5.74)$ & $1.03-2.99(3.19-9.27)$ & $1.83(5.67)$ & 0.45 \\
-3 & $1.84(5.70)$ & $1.20-3.16(3.72-9.79)$ & $1.80(5.58)$ & 0.49 \\
-2 & $1.83(5.67)$ & $1.06-2.79(3.28-8.64)$ & $1.82(5.64)$ & 0.47 \\
-1 & $1.81(5.61)$ & $1.03-3.18(3.19-9.85)$ & $1.79(5.55)$ & 0.51 \\
1 & $1.84(5.70)$ & $1.18-2.91(3.65-9.02)$ & $1.77(5.49)$ & 0.53 \\
2 & $1.87(5.80)$ & $1.17-2.94(3.62-9.11)$ & $1.82(5.64)$ & 0.49 \\
3 & $1.85(5.74)$ & $0.94-3.90(2.82-2.09)$ & $1.76(5.46)$ & 0.53 \\
5 & $1.82(5.64)$ & $0.85-3.49(2.63-0.81)$ & $1.75(5.43)$ & 0.53 \\
\hline
\end{tabular}

${ }^{a}$ Patients typically have one serum phosphate drawn each month. $-5=$ five months prior to intervention, $5=$ five months after intervention

Table 4 The Beliefs about Medicines Questionnaire (BMQ), scores before and after intervention

\begin{tabular}{|c|c|c|c|c|}
\hline BMQ Subscale & $\begin{array}{l}\text { Before intervention } \\
\text { Mean score }\end{array}$ & $\begin{array}{l}\text { After intervention } \\
\text { Mean score }\end{array}$ & Change in score $(95 \% \mathrm{Cl})$ & $p$ value \\
\hline $\begin{array}{l}\text { Specific-Necessity } \\
\text { (5 items, score range } 5-25)\end{array}$ & 18.2 & 19.2 & 1.0 & 0.005 \\
\hline -My health, at present, depends on my phosphate binder(s) & 4.0 & 4.1 & 0.1 & 0.450 \\
\hline -My life would be impossible without my phosphate binder(s) & 3.3 & 3.5 & 0.2 & 0.040 \\
\hline -Without my phosphate binder(s) I would be very ill & 3.4 & 3.7 & 0.3 & 0.050 \\
\hline -My health in the future will depend on my phosphate binder(s) & 3.6 & 3.8 & 0.2 & 0.150 \\
\hline -My phosphate binder(s) protect me from becoming worse & 3.8 & 4.1 & 0.3 & 0.010 \\
\hline $\begin{array}{l}\text { Specific-Concerns } \\
(6 \text { items, score range } 6-30)\end{array}$ & 15.3 & 13.8 & -1.5 & 0.002 \\
\hline -Having to take my phosphate binder(s) worries me & 2.3 & 2.1 & -0.2 & 0.070 \\
\hline $\begin{array}{l}\text {-I sometimes worry about the long-term effects of my } \\
\text { phosphate binder(s) }\end{array}$ & 2.9 & 2.5 & -0.4 & 0.040 \\
\hline -My phosphate binder(s) are a mystery to me & 2.9 & 2.5 & -0.4 & 0.030 \\
\hline -My phoshphate binder(s) disrupt my life & 2.5 & 2.2 & -0.3 & 0.040 \\
\hline $\begin{array}{l}\text {-I sometimes worry about becoming too dependent on my } \\
\text { phosphate binder(s) }\end{array}$ & 2.4 & 2.2 & -0.2 & 0.050 \\
\hline -My phosphate binder(s) give(s) med unpleasant side effects & 2.3 & 2.3 & 0.0 & 1.000 \\
\hline $\begin{array}{l}\text { General-Overuse } \\
\text { (4 items, score range } 4-20)\end{array}$ & 11.4 & 11.8 & 0.4 & 0.177 \\
\hline $\begin{array}{l}\text { - If doctors had more time with patients they would } \\
\text { prescribe fewer medicines }\end{array}$ & 3.1 & 3.2 & 0.1 & 0.030 \\
\hline -Doctors use too many medicines & 3.0 & 3.0 & 0.0 & 1.000 \\
\hline -Doctors place too much trust on medicines & 2.9 & 3.1 & 0.2 & 0.090 \\
\hline -Natural remedies are safer than medicines & 2.4 & 2.4 & 0.0 & 1.000 \\
\hline $\begin{array}{l}\text { General-Harm } \\
(4 \text { items, score range } 4-20\end{array}$ & 10.1 & 9.9 & -0.2 & 0.624 \\
\hline -Most medicines are addictive & 2.7 & 2.9 & 0.2 & 0.110 \\
\hline -Medicines do more harm than good & 2.3 & 2.2 & -0.1 & 0.450 \\
\hline $\begin{array}{l}\text {-People who take medicines should stop their treatment } \\
\text { for a while every now and again }\end{array}$ & 2.5 & 2.2 & -0.3 & 0.030 \\
\hline -All medicines are poisons & 2.6 & 2.6 & 0.0 & 1.000 \\
\hline
\end{tabular}


patients' beliefs in the necessity of phosphate binders were higher than their concerns both before and after the intervention. The study demonstrated a statistically significant increase in mean 'Specific-Necessity' scores and decrease in mean 'Specific- Concern' scores after intervention, while no change was seen in the mean scores for 'General-Overuse' and 'General-Harm'. Also, there was a positive change in the 'Necessity-Concern' differential after intervention (mean change in scores: 2.5, CI: $1.201,3.855 ; p=0.001$ ). The patients believed more in the importance of taking the phosphate binder and were less concerned about the side effects after the intervention.

The mean number of scores for correct answers in the 'Patient Knowledge' questionnaire, in the total study group, was relatively low prior to the intervention: 5.0 of a possible maximum total score of 16.0. A positive change after the intervention was seen by a statistically significant increase in scores for correct answers (mean change in scores: 2.9 , CI: 2.165, 3.570; $p=0.001$ ). The mean number of wrong answers was 1.0 both before and after intervention, while the mean number of the answer "I do not know" decreased from 3.0 to 1.5 (mean change in number: -1.5 , CI: $-2.005,-1.051 ; p=0.001$ ). Most frequently prior to intervention, the questions "When should you take the phosphate binder?" and "What should you do if you have forgotten to take the phosphate binder?" were answered correctly; 91\% (48) and $79 \%$ (42) correct answers, respectively. Few patients knew the answer to the question "The phosphate binder may affect the uptake of the following medicines"; before intervention only six patients had one correct choice and no patients had more than one of a possible total of three correct choices to this question. The highest increase in correct choices after intervention was seen for the questions "For which condition are you using phosphate binder?", "What can the use of phosphate binder prevent?" and "Which of these foods/drinks are especially rich in phosphate?". The mean number of correct choices for each question adjusted for the number of possible correct choices, increased from $0.51,0.19$ and 0.52 to $0.77,0.42$ and 0.76 respectively.

\section{Discussion}

This study shows that education and counselling about the use of phosphate binders have a positive effect on the dialysis patients' knowledge about the medicines, increase their sense of necessity of the treatment and reduce their concerns. This positive effect was reflected in an increased probability of serum phosphate being below the target threshold value $1.80 \mathrm{mmol} / \mathrm{L}(5.58 \mathrm{mg} / \mathrm{dL})$, although not statistically significant. The intervention did not affect the mean serum phosphate in the total study group nor the self-reported adherence.
The limited effect on serum phosphate and adherence could be due to the intervention being insufficient, including one information session only. Van Camp et al [11] investigated the effect of a 13-week nurse-led education and counselling on the adherence to phosphate binders. Adherence was evaluated before and after the intervention, which included both education about phosphate binders and thereafter bi-weekly individual counselling. They found that the intervention led to increase in adherence from 83 to $94 \%$ in the intervention group, while in the control group the adherence decreased from 86 to $76 \%$. Moreover mean serum phosphate levels decreased from 4.9 to $4.3 \mathrm{mg} / \mathrm{dL}$ (1.58 to $1.38 \mathrm{mmol} / \mathrm{L}$ ). Another explanation to this discrepancy in results could be the power of our study being insufficient. It was, however, not possible to extend the study population beyond the limit of the patient baseline of 120 , as the patients were included during a limited period of time, to avoid spill-over effect. Also, it was not possible to perform a randomised controlled study because of the proximity of patient chairs during the intervention.

Individual variability in pharmacological response to the phosphate binder, diet and absorption of phosphate, in addition to the individual variety in residual kidney function and dialytic removal of phosphate will influence on the level of serum phosphate [21-25]. This study does not include measurable variables such as vitamin D use, cinacalcet use, phosphate binder dosing, diet and changes in such variables that could have affected the serum phosphate levels during the study period.

Apparently, the self-reported adherence in this study was high ( $>22$ ) both before and after intervention, which gives little room for measuring improvement by the MARS-5 scale. The realtively high level of self-reported adherence seems to be in conflict with results from other studies stating that non-adherence is prevalent in dialysis patients, although a wide variation in rates of non-adherence is reported. The variation can be explained by differences in definitions and methods [4, 6]. There is an inconsistency in the published literature regarding the use of cut-off limits defining patients as adherent or non-adherent. In this study, no specific cut-off limit was defined in accordance with the method described by Horne and Weinman [8]. Others have defined adherence as a MARS- 5 score of $>20$ or $>23[26,27]$.

Van Camp et al [11] measured adherence for 17 consecutive weeks using the electronic Medication Event Monitoring System $\left(\mathrm{MEMS}^{\circ}\right)$. In addition, pillcount and self-report were used to corroborate the MEMS $^{\ominus}$ data. Evaluation of adherence over time was investigated and compared with historical data from an observational cohort study. In the intervention group adherence increased during the study period, 
while in the control group adherence declined. In our study, self-reported adherence was not validated by counting of tablet or other objective methods, which adds an uncertainty when interpreting the scores from MARS-5. Patients might feel pressured to provide a desirable response rather than an accurate assessment of their adherence [10]. Also, the study pharmacist uncovered examples of misunderstandings potentially influencing the results, like a patient who thought the phosphate binder was a painkiller, and did not take it because he did not have any pain. This patient was under the impression that he did not have phosphate binders on his medication list. These findings also highlights the issue regarding the sensitivity of MARS-5 as a tool for measuring adherence in this patient group.

The aforementioned patient was using multi-dose drug dispensing aid (MDD). Multi-dose drug dispensing is offered to patients, mostly elderly, with regular medication use combined with difficulties in handling and administering their drugs. The patients get their drugs machine dispensed into one unit bag for each dose occasion. The dose unit bags are labeled with patient data, drug contents, date and time for intake [28]. MDD users report more remoteness of their drugs and less knowledge about the indications for their drugs compared to non-MDD users [29]. The patient's lack of knowledge about the indications and his inability to identify the tablets in the MDD, lead the patient to poor adherence and to unintentionally not take the phosphate binders he needed. Individual counselling of the patient revealed this lack of knowledge and gave the patient the information he needed to make a knowledge-based choice and take the phosphate binders as intended.

Patients may be intentionally or non-intentionally non-adherent to treatment [23, 30-32]. During counselling, study patients reported challenges such as forgetfulness, denial of necessity, social embarrassment by taking tablets in company with others, impracticality with bringing tablets/ not having a proper container for bringing tablets, discomfort (taste, not allowed to swallow with fluid etc.), tablet burden and side effects (nausea, diarrhoea, constipation, stomach ache). One example of intentional non-adherence, expressed by some patients, was the decision that quality of life was more important than living longer. Cognitive function has been demonstrated in the literature to be lower while the patient is receiving dialysis than in between dialysis sessions [33]. For practical reasons like lack of facilities and logistic challenges, we could not administer the questionnaires prior to dialysis. This might have affected the patients understanding of the questionnaires and their ability to fill out the survey accurately. The majority of patients in our study were male $(70 \%)$ more than 60 years old (83\%), who had been treated with dialysis for a long time (mean; 34 months). Cognitive impairment in dialysis patients is well documented and could influence the effect of the intervention and overall adherence [34-37]. Considering the relatively high median age (72) of the study population and the possible cognitive impairment, scores for cognitive function could have been part of the inclusion criteria. Wileman used mini mental status evaluation (MMSE) with a certain score as inclusion criteria [23]. However, excluding patient with these challenges would have given overoptimistic results regarding effect, as cognitive impairment is common in the study population. During counselling, some of the patients told that their family members helped them with their medicines and reminded them to take the phosphate binder. This implies that relatives should be given the same information as the patients regarding medication treatment.

Educational interventions may have the greatest effect immediately following intervention and then this may wane over time. We assessed the questionnaires pre-intervention and then up to 4 weeks post-intervention. An assessment of the questionnaires immediately following intervention might have shown higher scores. In the perspective of patient safety and benefit, assessment of the questionnaires after a period of time provide a more realistic measurement of effect.

Our study increased the patients' level of knowledge on how to control their phosphate levels, especially when it comes to why they should take their phosphate binders. This knowledge might be important for patients' motivation for being adherent.

\section{Conclusions}

Short term one-to-one individualized pharmacist-led education and counselling about phosphate binders increased the probability of serum phosphate concentrations being below the target threshold level $1.80 \mathrm{mmol} / \mathrm{L}$ $(5.58 \mathrm{mg} / \mathrm{dL})$, although not statistically significant. However it did not decrease the mean serum phosphate level or increase the patients' self-reported adherence. The patients increased their knowledge about the phosphate binder and their understanding of adherence, and were less concerned about the side effects of the medication.

\section{Abbreviations}

BMQ: Beliefs about Medicines Questionnaire; CKD: Chronic Kidney Disease; MARS-5: Medication Adherence Report Scale; MDD: Multidose Drug Dispensing; MEMS ${ }^{\oplus}$ : Medication Event Monitoring System; MMSE: Mini Mental Status Evaluation

\section{Acknowledgments}

We wish to thank the staff at the Dialysis Department at Akershus University Hospital for their contribution to the conduct of the study. 


\section{Funding}

This work has been funded by The Hospital Pharmacies Enterprise, South Eastern Norway, by regular salary to authors employed by the funding body. The funding body had no commercial interest in the study.

\section{Availability of data and materials}

The datasets analysed during the current study are available from the corresponding author on reasonable request.

\section{Authors' contributions}

Research idea and study design: $\mathrm{BJH}, \mathrm{KB}, \mathrm{LM}, J \mathrm{CL}, \mathrm{KBJE}$. Data acquisition: BJH. Data analysis/interpretation: BJH, KB, LM, JCL, KBJE. Each author contributed important intellectual content during manuscript drafting or revision and accepts accountability for the overall work. All authors read and approved the final manuscript.

\section{Ethics approval and consent to participate}

Patients recruited signed informed consent to participation in advance. The Regional Committee for Medical and Health Research Ethics approved the study in advance (Document-id: 2016/1996). The data protection officer at the hospital approved the study in advance (Document-id: 17-027).

\section{Consent for publication}

Not applicable.

\section{Competing interests}

The authors declare that they have no competing interests.

\section{Publisher's Note}

Springer Nature remains neutral with regard to jurisdictional claims in published maps and institutional affiliations.

\section{Author details}

${ }^{1}$ Hospital Pharmacies Enterprise, South Eastern Norway, Stenersgate 1, PB. 79, 0050 Oslo, Norway. ${ }^{2}$ Department of Pharmaceutical Biosciences, School of Pharmacy, University of Oslo, Oslo, Norway. ${ }^{3}$ Health Services Research Units, Akershus University Hospital, Institute of Clinical Medicine, University of Oslo, Oslo, Norway.

Received: 26 November 2018 Accepted: 12 April 2019

Published online: 17 May 2019

\section{References}

1. Kestenbaum B, Sampson JN, Rudser KD, Patterson DJ, Seliger SL, Young B, et al. Serum phosphate levels and mortality risk among people with chronic kidney disease. J Am Soc Nephrol. 2005;16(2):520-8.

2. Eddington $H$, Hoefield R, Sinha S, Chrysochou C, Lane B, Foley RN, et al. Serum phosphate and mortality in patients with chronic kidney disease. Clin J Am Soc Nephrol. 2010;5(12):2251-7.

3. Palmer SC, Hayen A, Macaskill P, Pellegrini F, Craig JC, Elder GJ, et al. Serum levels of phosphorus, parathyroid hormone, and calcium and risks of death and cardiovascular disease in individuals with chronic kidney disease: a systematic review and meta-analysis. JAMA. 2011;305(11):1119-27.

4. Karamanidou C, Clatworthy J, Weinman J, Horne R. A systematic review of the prevalence and determinants of nonadherence to phosphate binding medication in patients with end-stage renal disease. BMC Nephrol. 2008;9:2.

5. Arenas MD, Malek T, Gil MT, Moledous A, Alvarez-Ude F, Reig-Ferrer A. Challenge of phosphorus control in hemodialysis patients: a problem of adherence? Journal of nephrology. 2010;23(5):525-34.

6. Ghimire S, Castelino RL, Lioufas NM, Peterson GM, Zaidi ST. Nonadherence to medication therapy in Haemodialysis patients: a systematic review. PLoS One. 2015;10(12):e0144119.

7. Horne R, Weinman J. Patients' beliefs about prescribed medicines and their role in adherence to treatment in chronic physical illness. J Psychosom Res. 1999:47(6):555-67.

8. Horne R, Weinman J. Self-regulation and self-management in asthma: exploring the role of illness perceptions and treatment beliefs in explaining non-adherence to preventer medication. Psychol Health. 2002;17(1):17-32.

9. Theofilou P. Medication adherence in Greek hemodialysis patients: the contribution of depression and health cognitions. Int J Behav Med. 2013; 20(2):311-8
10. Wileman V, Farrington K, Wellsted D, Almond M, Davenport A, Chilcot J. Medication beliefs are associated with phosphate binder non-adherence in hyperphosphatemic haemodialysis patients. Br J Health Psychol. 2015;20(3): 563-78.

11. Van Camp YP, Huybrechts SA, Van Rompaey B, Elseviers MM. Nurse-led education and counselling to enhance adherence to phosphate binders. J Clin Nurs. 2012;21(9-10):1304-13.

12. Sandlin K, Bennett PN, Ockerby C, Corradini AM. The impact of nurse-led education on haemodialysis patients' phosphate binder medication adherence. Journal of renal care. 2013;39(1):12-8.

13. Cooney D, Moon H, Liu Y, Miller RT, Perzynski A, Watts B, et al. A pharmacist based intervention to improve the care of patients with CKD: a pragmatic, randomized, controlled trial. BMC Nephrol. 2015;16:56.

14. Lim E, Hyun S, Lee JM, Kim S, Lee MJ, Lee SM, et al. Effects of education on low-phosphate diet and phosphate binder intake to control serum phosphate among maintenance hemodialysis patients: a randomized controlled trial. Kidney research and clinical practice. 2018;37(1):69-76.

15. Berkoben M, Quarles L. Management of hyperphosphatemia in chronic kidney disease. Wolters Kluwer; 2018. https:/www.uptodate.com/contents/ management-of-hyperphosphatemia-inchronic-kidney-disease?csi=e8792c65798f-4930-96bd-06085c7e9172\&source=contentshare. [cited 28th June 2018].

16. Eknoyan G. Meeting the challenges of the new K/DOQI guidelines. Am J Kidney Dis. 2003;41(5 Suppl):3-10.

17. Eide TH, Nilsson N, Kjeldby C, Dahle G, Refsum N. Rådgivning til pasienter som behandles med warfarin. Norsk Farmaceutisk Tidsskrift. 2012;5:19-22.

18. Horne R, Hankins M. The medication adherence report scale (MARS). 2004

19. Jonsdottir H, Friis S, Horne R, Pettersen Kl, Reikvam A, Andreassen OA. Beliefs about medications: measurement and relationship to adherence in patients with severe mental disorders. Acta Psychiatr Scand. 2009;119(1):78-84.

20. Jonsdottir H, Opjordsmoen S, Birkenaes AB, Engh JA, Ringen PA, Vaskinn A, et al. Medication adherence in outpatients with severe mental disorders: relation between self-reports and serum level. J Clin Psychopharmacol. 2010;30(2):169-75

21. Sherman RA. Hyperphosphatemia in Dialysis patients: beyond nonadherence to diet and binders. Am J Kidney Dis. 2016;67(2):182-6.

22. Block GA, Wheeler DC, Persky MS, Kestenbaum B, Ketteler M, Spiegel DM, et al. Effects of phosphate binders in moderate CKD. J Am Soc Nephrol. 2012;23(8):1407-15.

23. Wileman V, Chilcot J, Norton S, Hughes L, Wellsted D, Farrington K. Choosing not to take phosphate binders: the role of dialysis patients' medication beliefs. Nephron Clin Pract. 2011;119(3):c205-13.

24. Lornoy W, De Meester J, Becaus I, Billiouw JM, Van Malderen PA, Van Pottelberge M. Impact of convective flow on phosphorus removal in maintenance hemodialysis patients. J Ren Nutr. 2006;16(1):47-53.

25. Ramirez JA, Emmett M, White MG, Fathi N, Santa Ana CA, Morawski SG, et al. The absorption of dietary phosphorus and calcium in hemodialysis patients. Kidney Int. 1986;30(5):753-9.

26. Ediger JP, Walker JR, Graff L, Lix L, Clara I, Rawsthorne P, et al. Predictors of medication adherence in inflammatory bowel disease. Am J Gastroenterol. 2007; 102:1417

27. Sjolander M, Eriksson M, Glader EL. The association between patients' beliefs about medicines and adherence to drug treatment after stroke: a crosssectional questionnaire survey. BMJ Open. 2013;3(9):e003551.

28. Johnell K, Fastbom J. Multi-dose drug dispensing and inappropriate drug use: a nationwide register-based study of over 700,000 elderly. Scand J Prim Health Care. 2008;26(2):86-91.

29. Kwint HF, Stolk G, Faber A, Gussekloo J, Bouvy ML. Medication adherence and knowledge of older patients with and without multidose drug dispensing. Age Ageing. 2013;42(5):620-6.

30. Haynes RB, Ackloo E, Sahota N, McDonald HP, Yao X. Interventions for enhancing medication adherence. The Cochrane database of systematic reviews. 2008;2:CD000011.

31. Wroe A, Thomas M. Intentional and unintentional nonadherence in patients prescribed HAART treatment regimens. Psychol Health Med. 2003;8(4):453-63.

32. Clifford S, Barber N, Horne R. Understanding different beliefs held by adherers, unintentional nonadherers, and intentional nonadherers: application of the necessity-concerns framework. J Psychosom Res. 2008; 64(1):41-6.

33. Murray AM. Cognitive impairment in the aging dialysis and chronic kidney disease populations: an occult burden. Adv Chronic Kidney Dis. 2008;15(2): 123-32. 
34. O'Lone E, Connors M, Masson P, Wu S, Kelly PJ, Gillespie D, et al. Cognition in people with end-stage kidney disease treated with hemodialysis: a systematic review and meta-analysis. Am J Kidney Dis. 2016;67(6):925-35.

35. Kalirao P, Pederson S, Foley RN, Kolste A, Tupper D, Zaun D, et al. Cognitive impairment in peritoneal dialysis patients. Am J Kidney Dis. 2011;57(4):612-20.

36. Pereira AA, Weiner DE, Scott T, Chandra P, Bluestein R, Griffith J, et al. Subcortical cognitive impairment in dialysis patients. Hemodial Int. 2007; 11(3):309-14.

37. Murray AM, Tupper DE, Knopman DS, Gilbertson DT, Pederson SL, Li S, et al. Cognitive impairment in hemodialysis patients is common. Neurology. 2006; 67(2):216-23.

38. Elliott RA. Appropriate use of dose administration aids. Aust Prescr. 2014; 37(2):46-50

Ready to submit your research? Choose BMC and benefit from:

- fast, convenient online submission

- thorough peer review by experienced researchers in your field

- rapid publication on acceptance

- support for research data, including large and complex data types

- gold Open Access which fosters wider collaboration and increased citations

- maximum visibility for your research: over $100 \mathrm{M}$ website views per year

At BMC, research is always in progress.

Learn more biomedcentral.com/submissions 